\title{
ABOVEGROUND PREDATION BY AN AMERICAN BADGER (TAXIDEA TAXUS) ON BLACK-TAILED PRAIRIE DOGS (CYNOMYS LUDOVICIANUS)
}

\author{
David Austin Eads ${ }^{1,2}$ and Dean Edwin Biggins 1,3
}

\begin{abstract}
During research on black-tailed prairie dogs (Cynomys ludovicianus), we repeatedly observed a female American badger (Taxidea taxus) hunting prairie dogs on a colony in southern Phillips County, Montana. During 1-14 June 2006, we observed 7 aboveground attacks (2 successful) and 3 successful excavations of prairie dogs. The locations and circumstances of aboveground attacks suggested that the badger improved her probability of capturing prairie dogs by planning the aboveground attacks based on perceptions of speeds, angles, distances, and predicted escape responses of prey. Our observations add to previous reports on the complex and varied predatory methods and cognitive capacities of badgers. These observations also underscore the individuality of predators and support the concept that predators are active participants in predator-prey interactions.
\end{abstract}

Key words: badger, Taxidea taxus, prairie dog, Cynomys ludovicianus, predation.

American badgers (Taxidea taxus) are mustelid carnivores of the grasslands of North America that primarily prey upon grounddwelling rodents, especially sciurids such as ground squirrels (Spermophilus), marmots (Marmota), and prairie dogs (Cynomys). Badgers are capable of several hunting techniques (reviewed in Michener 2004), but they typically pursue prey by excavation (Lindzey 2003). During excavations, badgers are known to use surrounding soil (Knopf and Balph 1969) or objects (Michener 2004) to plug burrow openings, or to associate with coyotes (Canis latrans) while hunting (Minta et al. 1992), thereby directly or indirectly blocking escape routes of sciurids. Although few reports are available, observations suggest that badgers also pursue and capture sciurids above ground (e.g., Michener 2004).

From 1 June to 14 June 2006, we observed predatory behavior of a single female badger toward black-tailed prairie dogs (C. ludovicianus) inhabiting an 11-ha colony adjacent to the northern border of UL Bend National Wildlife Refuge in southern Phillips County, Montana. Vegetative cover on the colony was predominantly grasses, mostly western wheatgrass (Pascopyrum smithii) and blue grama (Bouteloua gracilis). We observed this badger carrying out 7 aboveground attacks on prairie dogs; 2 of these attacks resulted in successful captures, a phenomenon previously reported with little detail (Cahalane 1950). We also observed the badger excavating prairie dog burrows on 2 occasions, which also resulted in successful captures. Herein, we only describe successful aboveground attacks and excavations.

We observed predation events with a 25power telescope positioned approximately 120 $\mathrm{m}$ from the home burrow, hereafter termed "den," of the badger. At the end of each observation day, we recorded key locations with global positioning receivers and collected measures of distances (to the nearest meter) between key locations with a tape measure. Because sciurids might select multi-entrance burrow systems when attacked by semifossorial predators (e.g., Turner 1973), we identified the number of entrances per prairie dog burrow system in the immediate vicinity of aboveground attacks on prairie dogs. We used a Craftsman ${ }^{\circledR}$ leafblower to force air into a burrow entrance and simultaneously used feathers to detect outward airflow at nearby burrow entrances. Excavations by the badger might have plugged the burrow systems; thus, we did not use leafblowers to determine numbers of holes for excavated burrows.

On 1 June, we first observed the female badger and her 2 young. At 11:14 (MDT), the badger rapidly emerged from her den (Fig. 1) to pursue an adult prairie dog that was foraging

\footnotetext{
${ }^{1}$ U.S. Geological Survey (BRD), Fort Collins Science Center, 2150 Centre Avenue, Building C, Fort Collins, CO 80526. 65211.

${ }_{2}^{2}$ Present address: Department of Fisheries and Wildlife Sciences, 302 Anheuser-Busch Natural Resources Building, University of Missouri, Columbia, MO

${ }^{3}$ Corresponding author. E-mail: dean_biggins@usgs.gov
} 

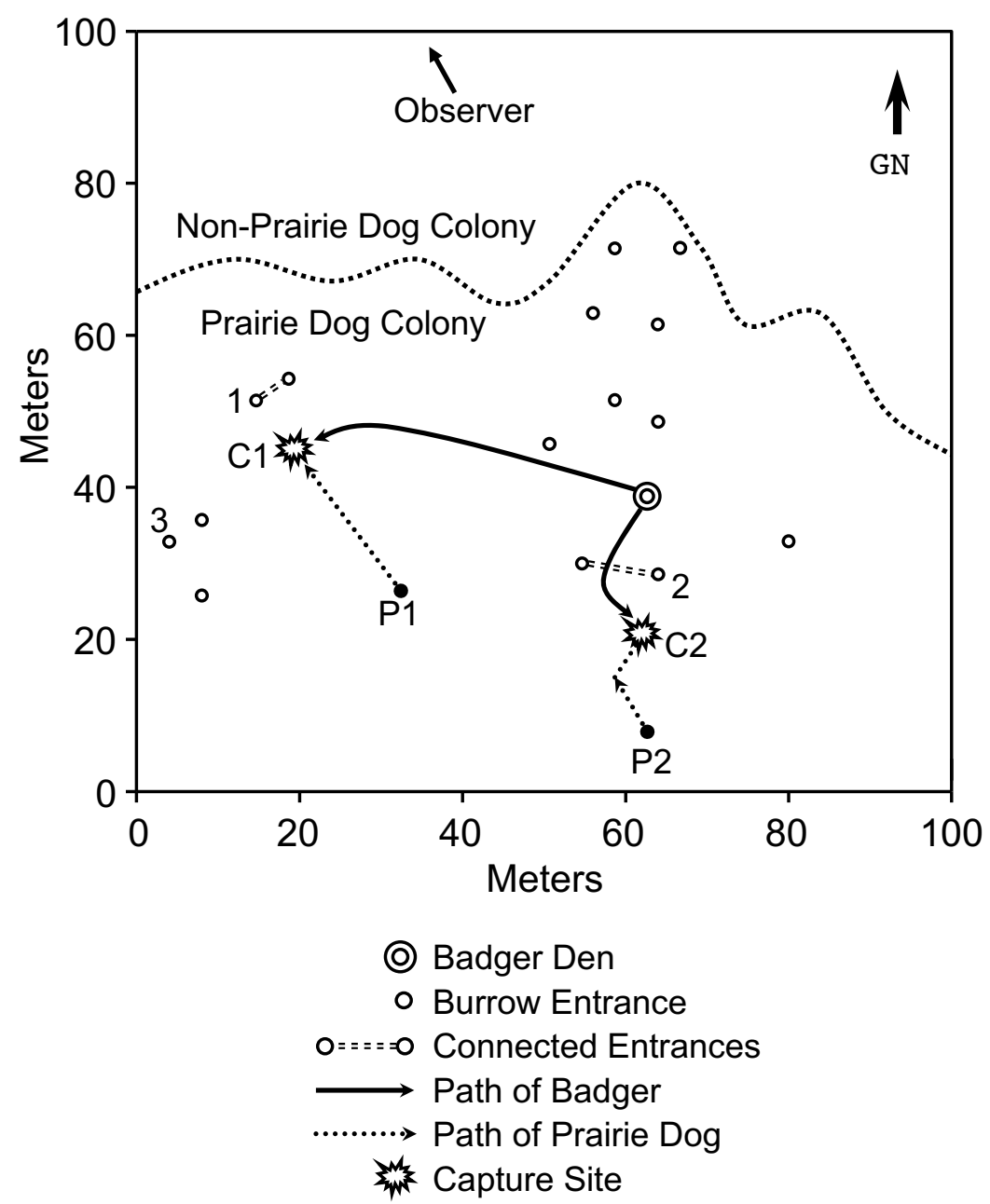

Fig. 1. Locations of a female American badger (Taxidea taxus) and black-tailed prairie dogs (Cynomys ludovicianus, P1 and P2) during 2 aboveground predation events (C1 and C2) and 1 excavation event (burrow entrance 3). Observations were made on an 11-ha prairie dog colony in southern Phillips County, Montana, 1-3 June 2006.

$33 \mathrm{~m}$ to the southwest at a location covered predominately by rocky substrate (Fig. 1, location P1). Juvenile prairie dogs in the area immediately entered a nearby multi-entrance burrow (Fig. 1, burrow 1). The adult being pursued and another adult ran toward the burrow occupied by the juvenile prairie dogs, which was located $20 \mathrm{~m}$ from the foraging location of the adults. The badger intercepted the 1st adult prairie dog (Fig. 1, location C1), and caught it with a bite to the nape. The other adult prairie dog entered the multi-entrance burrow system (Fig. 1, burrow 1). The badger carried the captured prairie dog to her den, which contained her young. At 14:25, the female badger emerged again from her den to pursue another adult prairie dog that was foraging about $25 \mathrm{~m}$ south of the den (Fig. 1, location P2). The targeted prairie $\operatorname{dog}$ and another nearby adult prairie dog retreated toward a multi-entrance burrow system (Fig. 1, burrow 2). The 1st prairie dog entered the western burrow entrance upon arrival, but the badger intercepted the 2nd adult prairie dog about $20 \mathrm{~m}$ from her den (Fig. 1, location C2). The prairie dog rolled onto its back in a defensive posture and emitted a loud (audible at $120 \mathrm{~m}$ ) distress call. The badger silenced the prairie dog with a bite to the throat and carried it to her den. 
Successful aboveground pursuits by the badger were initiated (before surrounding prairie dogs began to retreat) via those paths directed toward the burrow entrance apparently selected for escape by targeted prairie dogs, rather than via paths directed toward targeted prey, suggesting that the badger predicted the escape route of its prey. Direct pursuit of prey would have resulted in a different path than the one we observed in the 1st attack (Fig. 1). The escape path of the prairie dog in the 2nd successful aboveground attack seemed directed initially toward the western entrance of the connected system, accompanied by a similar intercept point in the path by the badger. After the prairie dog adjusted its flight toward the eastern entrance (Fig. 1, burrow 2), the badger made a counter-adjustment. In both instances, prairie dogs were intercepted rather than overtaken by badgers in direct pursuit.

On 2 June at 12:12, we observed the badger slowly emerging from her den. She then walked westward sniffing burrows. She oriented herself toward a tonically calling prairie dog and sprinted to its location (Fig. 1, burrow 3); the prairie dog entered the burrow. The badger sniffed the burrow and then began a frenzied bout of digging at 12:14. During excavation, a burrowing owl (Athene cunicularia) attacked the badger, diving and striking her on the back 3 times before retreating to a burrow located near the western periphery of the prairie dog colony. Periodically, the badger emerged, shook, perhaps to dislodge soil from her fur, and looked toward her den. The badger stopped digging at 12:51 and assumed a sprawled out position, presumably to rest. About 2 minutes later, the badger continued to excavate the burrow. At 13:20, the badger emerged, carrying an adult prairie dog ventrally by the thorax, which is consistent with observations of kill bites to Richardson's ground squirrels (S. richardsonii) that are excavated and killed by badgers (Michener and Iwaniuk 2001). The badger then carried the prairie $\operatorname{dog} 65 \mathrm{~m}$, and entered her den.

During our observations, the badger captured 2 additional prairie dogs via excavation. At 12:18 on 4 June 2006, the badger emerged from a burrow $141 \mathrm{~m}$ from her den carrying an adult prairie dog by the nape. About 1 minute later, the badger entered her den with the prey. Although the excavation was not observed, the hunting technique was confirmed by inspecting the burrow from which the badger had emerged; we observed the distinct fan-shaped soil deposit that is characteristic of badger excavations (Eldridge 2004).

At 10:05 on 14 June, the badger emerged, without a prairie dog, from a different burrow on the southern periphery of the colony. She slowly inspected surrounding burrows, selecting a hidden (nonmounded) burrow entrance (Hoogland 1995) $20 \mathrm{~m}$ away for excavation. About 11 minutes later, the badger emerged carrying an adult prairie dog dorsally by the thorax, again consistent with reports about Richardson's ground squirrels that were excavated and killed by badgers (Michener and Iwaniuk 2001). The badger then carried the prairie dog to her den. Overall, from 1 June to 14 June 2006, the female badger successfully captured prairie dogs during 2 of 7 (29\%) observed aboveground pursuits and 3 of 3 (100\%) excavations, suggesting that the badger used a variety of hunting techniques and did not simply adopt the novel aboveground strategy to the exclusion of excavation, the traditional hunting technique used by badgers (Lindzey 2003).

Aboveground pursuit of prairie dogs by badgers was reported by Smith (1967), who observed 2 unsuccessful chases, and by Cahalane (1950), who reported a colleague's description of an aboveground capture of a black-tailed prairie dog. The aboveground pursuit of a ground squirrel reported by Sawyer (1925) possibly culminated in a capture in a shallow burrow or other refuge. During her 15-year study on the ecology of Richardson's ground squirrels, Michener (2004) observed only 1 successful aboveground pursuit of a ground squirrel by a badger. While excavating a burrow, a badger flushed a juvenile squirrel and captured it after a $17-\mathrm{m}$ sprint. Three aboveground captures of ground squirrels by badgers observed by Schwab (1978) demonstrated 2 hunting tactics: ambush at a burrow entrance and aboveground pursuit of juvenile squirrels. Badgers have been observed to pursue yellow-bellied marmots (M. flaviventris) above ground (Thompson 1979, Armitage 2004, Blumstein et al. 2004), but aboveground captures were reported only for juvenile marmots (Thompson 1979). The accounts of Michener (2004), Schwab (1978), and Thompson (1979) reported circumstances somewhat similar to those of our observations, but timing and durations of events, as well as directions and distances traveled by predator 
and prey, were not described in sufficient detail to allow direct comparisons. Unlike our observations, juvenile prey were taken in all 11 attacks that these 3 authors described, suggesting that the badgers might have been able to rely on speed alone rather than on cognitive planning involving interception of prey.

Predation events, in general, are rarely observed (Armitage 1982), but the relative frequency of aboveground attacks by badgers on sciurid prey seems low. Despite observing prairie dogs for hundreds of thousands of hours collectively, including many observations of predation on prairie dogs by other species, neither J.L. Hoogland (personal communication) nor C.N. Slobodchikoff (personal communication) saw aboveground predation on prairie dogs by badgers. The prairie dog colonies that those researchers studied also were occupied by badgers; nearly $75 \%$ of the prairie dogs (C. gunnisoni) in a colony were killed by a single badger in 1 season (C.N. Slobodchikoff personal communication). In contrast to direct observations of predation, badger excavations are easily observed (personal observations) and identifiable by their distinct characteristics (Eldridge 2004), which might lead to overestimation of the frequency of digging as a hunting technique. Nevertheless, our observations on prairie dog colonies, including the observations detailed here, suggest that badgers commonly hunt prairie dogs via excavation, but some individuals use other hunting tactics that are apparently profitable in certain circumstances.

Reports of aboveground pursuit of sciurids by badgers suggest that such behavior might be used most frequently by maternal females. To our knowledge, all cases of such behavior in badgers of known sex involved maternal females observed during summer months (Sawyer 1925, Thompson 1979, Michener 2004, this study), suggesting that females might increase the frequency of such attacks when their energetic demands are high (Harlow et al. 1985). Nevertheless, the preponderance of summer observations might simply be due to an observation bias; most opportunities for observing ground squirrels, marmots, and prairie dogs by researchers have been in summer.

Our behavioral observations, coupled with records of fine-scale environmental variation, provide additional insight into the predatory and cognitive abilities of American badgers. Substrate characteristics and vegetation density might affect predation risk for prairie dogs. For example, yellow-bellied marmots run fastest across bare soil with low vegetation and slowest across stones or talus (Blumstein et al. 2004). In our study, prairie dogs targeted by the badger were on a stony substrate with sparse vegetation, although much of the prairie dog colony had packed soil with relatively few stones and moderate amounts of forage. Perhaps the female badger selected her den location in relation to substrate characteristics, thereby maximizing her chances of successful aboveground predation on prairie dogs.

Prey species might escape predation simply by avoiding areas occupied by their predators (Caro 2005). Unlike other sciurids that might avoid areas occupied by badgers and forage elsewhere (e.g., yellow-bellied marmots; Armitage 2004), movements of black-tailed prairie dogs are restricted by boundaries of coteries, areas inhabited by relatively permanent harempolygynous groups (Hoogland 1995). The badger that we observed denned and attacked prairie dogs foraging in a microhabitat further confined by the border of the colony (Fig. 1), suggesting that in addition to substrate characteristics, the badger might have selected her den location in relation to fine-scale distributions of prairie dogs.

Burrow configuration also might affect antipredator responses of prairie dogs and their risk of predation. Our observations showed that prairie dogs sometimes attempted to escape the approaching badger by submerging into multi-entrance burrows rather than singleentrance burrows (see also Turner 1973). Escape options afforded by multi-entrance systems might deter badger attacks via excavation. Although badgers can plug extra entrances before excavating the burrow (Knopf and Balph 1969, Michener 2004) or associate with coyotes while hunting (Minta et al. 1992), we did not observe such behaviors at our study site.

Although many prey species are sensitive to paths of predators (sensu Cooper 1998), there are few published records of the paths used by free-living carnivores during natural predation events. A bobcat (Lynx rufus) used a path of pursuit 16\% shorter than its fleeing cottontail (Sylvilagus) prey; given the conditions and estimated speeds of the 2 animals, the cottontail probably would not have been captured before it reached its presumed burrow if it had been pursued directly (Biggins and Biggins 
2006). Similarly, on 2 separate occasions after observing marmots moving away from burrows, coyotes pursued a targeted marmot by using an angle of attack that "cut off retreat" (Armitage 1982 , pp. 503, 505). Indeed, this type of tactical pursuit, rather than simply overtaking prey, is likely a common strategy (see Curio 1976:148-152). Perhaps paths of intercept are favored most by predators that commonly pursue prey that are entirely reliant on predictable refuges for escape, in contrast to nonrefuging species that might have multiple options for predator evasion; however, the escape paths of nonrefuging prey might still be somewhat predictable for terrestrial mammals due to other environmental variables (e.g., topography, substrate, and vegetation).

Our observations suggest that the badger was a responsive and strategic predator, potentially selecting predatory methods that afforded greater success depending on the location and behavior of prey (see also Quinn and Cresswell 2004). Perhaps the badger we observed had learned that prairie dogs foraged in specific patches of habitat and preferred specific escape routes, such as paths toward multientrance burrows. The badger's paths of pursuit suggest an ability to learn and remember locations of features in its environment (spatial learning; Shettleworth 1998) and to apply simple geometric calculations during its pursuit. Free-ranging badgers have the cognitive capacity to use tools (Michener 2004) and remember cache locations (Michener 2000), and they appear to have the additional capacity to plan attacks based on their perceptions of speeds, angles, distances, and predicted escape responses of prey. The opportunism of the badger is underscored by reports of other diverse hunting methods and prey, including predation on other mesocarnivores such as coyotes (Young and Jackson 1951), cooperative hunting with coyotes (Cahalane 1950, Kiliaan et al. 1991, Minta et al. 1992), and even capture of fish in shallow water (Drake and Presnall 1950).

Predators are sometimes presumed to be unresponsive to prey behaviors, and thus many theoretical and empirical evaluations of predator-prey interactions assume that predation risk is constant for prey species (Lima 2002). Variation in strategic hunting methods of individual predators, as illustrated here for a female American badger, creates a challenging task of risk assessment for prairie dogs and other prey species (Lima 2002). Our observations add to the increasing literature on the complex and varied predatory methods of badgers (e.g., Sawyer 1925, Balph 1961, Smith 1967, Minta et al. 1992, Armitage 2004, Michener 2004) and suggest that predators should be treated as individuals (Hayes and Jenkins 1997) and as active "participants" (Lima 2002) in predator-prey interactions.

We thank the Denver Zoological Foundation, the United States Bureau of Land Management, and the United States Geological Survey for funding the research that made these observations possible. We appreciate the reviews and comments of J. Truett, D. Jachowski, D. Appleby, K. Geluso, and an anonymous reviewer. Discussions on predator behaviors with S. Hunter, D.L. Eads, and T. Eads also were productive.

\section{Literature Cited}

Armitage, K.B. 1982. Marmots and coyotes: behavior of prey and predator . Journal of Mammalogy 63:503505 .

2004. Badger predation on yellow-bellied marmots. American Midland Naturalist 151:378-387.

BALPH, D.F. 1961. Underground concealment as a method of predation. Journal of Mammalogy 42:423-424.

Biggins, D.E., AND D.M. Biggins. 2006. A bobcat attack on a cottontail. Southwestern Naturalist 51:119-122.

Blumstein, D.T., A. Runyan, M. Seymour, A. Nicodemus, A. Ozgul, F. Ransler, S. Im, et al. 2004. Locomotor ability and wariness in yellow-bellied marmots. Ethology 110:615-634.

Cahalane, V.H. 1950. Badger-coyote "partnerships." Journal of Mammalogy 31:354-355.

CARo, T. 2005. Antipredator defenses in birds and mammals. University of Chicago Press, Chicago, IL.

COOPER, W.E. 1998. Direction of predator turning, a neglected cue to predation risk. Behaviour 135:55-64.

CURIO, E. 1976. The ethology of predation. Springer-Verlag Berlin Heidelberg, Germany.

Drake, G.E., and C.C. Presnall. 1950. A badger preying upon carp. Journal of Mammalogy 31:355-356.

ELDRIDGE, D.J. 2004. Mounds of the American badger (Taxidea taxus): significant features of shrub-steppe ecosystems. Journal of Mammalogy 85:1060-1067.

Harlow, H.J., B. Miller, T. Ryder, and L. Ryder. 1985. Energy requirements for gestation and lactation in a delayed implanter, the American badger. Comparative Biochemistry and Physiology, A. Comparative Physiology 82:885-889.

HAYES, J.P., AND S.H. JENKINS. 1997. Individual variation in mammals. Journal of Mammalogy 78:274-293.

HoOgLAND, J.L. 1995. The black-tailed prairie dog: social life of a burrowing mammal. University of Chicago Press, Chicago, IL. 
Kiliaan, H.P., C. Mamo, and P.C. Paquet. 1991. A coyote, Canis latrans, and badger, Taxidea taxus, interaction near Cypress Hills Provincial Park, Alberta. Canadian Field-Naturalist 105:122-123.

KNOPF, F.L., AND D.F. BALPH. 1969. Badgers plug burrows to confine prey. Journal of Mammalogy 50:635-636.

Lima, S.L. 2002. Putting predators back into behavioral predator-prey interactions. Trends in Ecology and Evolution 17:70-75.

Lindzey, F.G. 2003. Badger Taxidea taxus. Pages 683-691 in G.A. Feldhamer, B.C. Thompson, and J.A. Chapman, editors, Wild mammals of North America: biology, management, and conservation. 2nd edition. Johns Hopkins University Press, Baltimore, MD.

Michener, G.R. 2000. Caching of Richardson's ground squirrels by North American badgers. Journal of Mammalogy 81:1106-1117.

2004. Hunting techniques and tool use by North American badgers preying on Richardson's ground squirrels. Journal of Mammalogy 85:1019-1027.

Michener, G.R., AND A.N. Iwaniuk. 2001. Killing technique of North American badgers preying on Richardson's ground squirrels. Canadian Journal of Zoology 79:2109-2113.

Minta, S.C., K.A. Minta, and D.F. LotT. 1992. Hunting associations between badgers (Taxidea taxus) and coyotes (Canis latrans). Journal of Mammalogy 73: 814-820.
Quinn, J.L., And W. Cresswell. 2004. Predator hunting behaviour and prey vulnerability. Journal of Animal Ecology 73:143-154.

SAWYER, E.J. 1925. Badger runs down ground squirrels. Journal of Mammalogy 6:125-126.

SCHWAB, E.R. 1978. An observation of badger predation on Richardson ground squirrels. Prairie Naturalist 10:60-61.

Shettleworth, S.J. 1998. Cognition, evolution, and behavior. Oxford University Press, New York, NY.

Smith, R.E. 1967. Natural history of the prairie dog in Kansas. Miscellaneous Publication 49, University of Kansas Museum of Natural History, Lawrence, KS.

Thompson, S.E., JR. 1979. Socioecology of the yellow-bellied marmot (Marmota flaviventris) in central Oregon. Doctoral dissertation, University of California, Berkeley.

TuRnER, L.W. 1973. Vocal and escape responses of Spermophilus beldingi to predators. Journal of Mammalogy 54:990-993.

YounG. S.P., AND H.H.T. JACKsON. 1951. The clever coyote. Wildlife Management Institute and University of Nebraska Press, Lincoln. 411 pp.

Received 14 March 2007 Accepted 7 February 2008 